\title{
USE OF GAMING AND SIMULATION TO STUDY SELF-ORGANISING BEHAVIOUR OF VIRTUAL ENTERPRISES
}

\author{
Roger M. Kerr and Gang Wu \\ School of Mechanical and Manufacturing Engineering \\ University of New South Wales \\ Sydney 2052 \\ AUSTRALIA \\ r.kerr@unsw.edu.au
}

\begin{abstract}
This paper reports on the use of operational gaming in a simulated supply chain situation containing externally generated end-product demands and basic raw materials supplies, and involving a number of companies involved at three different stages of the production process. The gaming exercise was replicated a number of time over the Internet and a major conclusion was that in the environment simulated, spontaneous "virtual enterprises" tended to form, with the characteristics of mutual trust and co-operation rather than economic rationalism. The specific gaming environment and rules under which the exercise was conducted are presented and the results and conclusions are discussed.
\end{abstract}

\section{INTRODUCTION}

Today's globally competitive environment fosters the formation of long term alliances, between organisations operating at different stages of the supply chain, can be a powerful competitive weapon. Indeed, competition in many industries is already seen as being not between companies but between co-operative enterprises. The spread of this phenomenon has been boosted by new technology-driven opportunities, which are making available almost any degree of potential integration between individual company's information systems, and allowing almost instantaneous transmission of complex data information over global distances (1), (2).

In many cases, such "virtual enterprises" consist of loose alliances between several companies, either through a series of independent co-operative agreements between pairs of individual companies, or through some centralised co-ordinating body. The evolutionary behaviour of such enterprises, and the problems of managing them, are likely to be very different from those confronting an organisation with a single management body, and a single set of objectives. However, because of the recency of the phenomenon, and the long time scales required to study it, empirical research on these topics is sparse. Studies on the evolution of virtual enterprises are generally based either on anecdotal evidence, latitudinal analysis of individual 
enterprises at particular points of time (usually conducted by different researchers), or in-depth case studies of specific enterprises. None of these techniques provides a suitable research platform for the systematic study of how virtual enterprises may evolve over time, or the management issues involved.

A technique that at least partially overcomes these limitations, is that of operational gaming, used extensively in the past in a military context for the exploration of alternative military strategies, in environments in which competitors may make unpredictable moves. In operations management, games have been used extensively for educational purposes (3), but less as a systematic research tool for the examination of the effects of different behaviour patterns of companies operating in a competitive environment.

This paper reports some preliminary results, obtained from the use of gaming techniques, to simulate the development and behaviour of virtual enterprises involved specifically in a manufacturing supply chain environment. The gaming was carried out at a sufficient degree of detail to capture the key parameters associated with enterprise formation and operation, but at a level of aggregation such that critical issues are not obscured by detail. Emphasis was placed in designing a competitive environment (with individual companies simulated by individual people) which although a major simplification of reality, was sufficiently combinatorially complex in terms of any individual decision making problem as to hopefully be a reflection of the existence or otherwise of cooperative behaviour in competitive environments, rather a reflection at any individual ability at mathematical optimisation.

\section{THE SIMULATED ENVIRONMENT}

The industrial environment comprises of a set of sixteen potentially interacting companies, each company being represented by one player. Companies are divided into front-end suppliers (four companies), first tier suppliers (four companies) second tier suppliers (four companies) and third tier (back end) suppliers (four companies)

This arrangement is shown in Fig 1. Each of the "front end" companies will experience a market demand for four products $\mathrm{A}, \mathrm{B}, \mathrm{C}$ and $\mathrm{D}$ which in turn are made from different combinations of components $\mathrm{U}, \mathrm{V}, \mathrm{W}$ and $\mathrm{X}$. These components are manufactured by the first tier suppliers from different combinations of components $\mathrm{M}, \mathrm{N}, \mathrm{O}$ and $\mathrm{P}$ which in turn are manufactured by the second tier suppliers from different combinations of $\mathrm{H}, \mathrm{I} \mathrm{J}$ and $\mathrm{K}$, back to basic raw materials $\mathrm{E}, \mathrm{F} \mathrm{G}$ and $\mathrm{H}$.

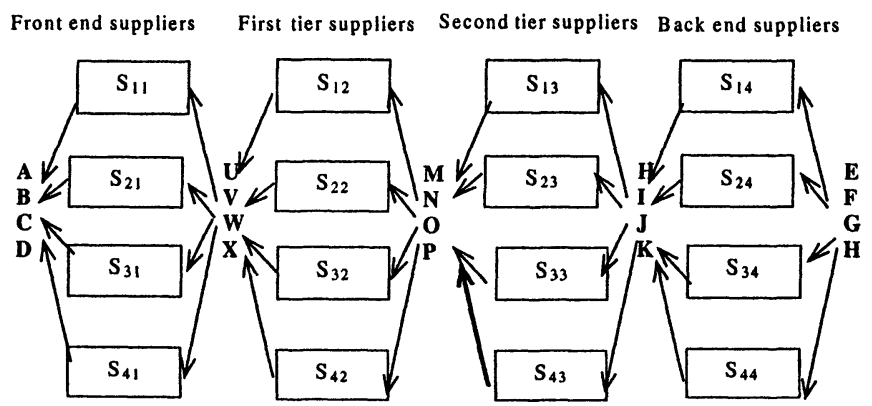

Figure 1 - The Supply Chain 
The projected market for each of the four end-products is assumed to be known on a month by month basis for the next 12 months, but the actual demand will be subject to random variation of plus or minus $10 \%$. Projected markets for each product for the succeeding four years are given in terms of the forecast market for the whole year, but with possible variations of up to plus or minus $20 \%$ per year being possible from the forecast.

The simulation is performed by individual players communicating over the internet, with the various rules, constraints, market demands, and stochastic events being determined by background, pre-programmed algorithms.

The expected total market for each product is provided to each front end supplier in the form of forecast units every month for the next 12 months. These companies can quote a price for that product for any or all of the twelve month periods (the price may be the same for each period or may be varied by period). Market share in each period will be based on the price a company offers in relation to the current offers of the competing companies. Computation of market share is automatically performed by an algorithm containing price-demand elasticity curves for each product (which are not revealed to any of the individual companies) in which the total demand is distributed proportionally across companies quoting prices for those products according to price quoted and the price-demand elasticity curves.

Each company (including supplier companies) has an identical fixed normal production capacity per month, which may be used for production of any of the items a company is qualified to produce. However for each month in which more than one item is produced, a $10 \%$ reduction of normal capacity is imposed for each addition item produced in that month. This is intended to reflect the fact that "changeover times" are required between items, and that production costs can be reduced with long production runs of the same item. Total normal production capacity for each company is set at approximately $25 \%$ of total market.

Companies will incur both production and inventory holding costs on a period by period basis. A single unit of each item will have the same production cost as any other item. Up to $25 \%$ increase in capacity is allowed but with corresponding increase in production costs of $15 \%$ for each unit produced in excess of the normal capacity for that month. Inventory costs are assessed at $2 \%$ of the total value (production plus materials costs of finished good stocks and materials costs for raw materials stocks) for any stock they have at the end of a period.

\section{GAMING RULES}

The exercise starts with each front end company deciding on the product mix and price it will offer in each month for a 12 month planning horizon with price based on anticipated production and materials costs. The resulting market share of each company in terms of tentative orders for each product in each month for the next 12 months is computed, based on its product mix and price offered. Once a company has submitted its plan, the following rules apply:

- the first month of the plan is frozen as regards product mix and price.

- the next two months of the plan is frozen as regards product mix but prices may be changed 
- the remainder of the plan is flexible as regards both product mix and price; any company may at any time submit changes to either product mix or price for future periods in which it is allowed to do so.

When a company makes such changes, the market share of (in terms of production volumes) of each other company will change accordingly, causing dynamic changes in market share as individual companies vary their product mixes and prices.

Each company is responsible for ensuring adequate supplies of raw materials for each of the products it has decided to make. Based on their current proposed production, the front end companies compute their material requirements, and release orders to any one or to all of the first tier supplier companies, for any number of months up to a complete year. Each supplier can then make a bid for some or all of a potential customers business which will take the form of a statement of the specific periods in which the supplier is prepared to supply the item, the quantity that can be supplied, and the price.

Supplier bids may be converted to firm orders of the following types:

1. Firm order for the next month only at fixed price

2. Firm order for supply of specific quantities for a fixed number of months.

3. Firm order for the next month with blanket order for total cumulative quantity to be ordered over an agreed number of months at a fixed price.

Prices are completely flexible and negotiable between customer and supplier. However once a firm order is made, it takes the place of a contractually binding agreement. A customer can break such an agreement with a penalty that entitles the supplier to demand $20 \%$ of the value of the remaining unfilled orders at the time the agreement is broken. An agreement can also be regarded as terminated if a supplier fails to deliver the agreed quantity in the agreed month, in which case the customer can, if they wish, put remaining requirements out to open tender without penalty.

When first tier suppliers have established their own market commitments, they must decide on their own production plan to meet these commitments, and their own raw materials requirements to meet this plan. These raw materials requirements then serve as the basis for a bid-offer process to the next tier of suppliers and so on. Similar types of price negotiation and commitment to different types of firm order occurs with each tier. However, back end suppliers will have prices quoted to them by a pre-programmed supply algorithm which contains base level prices and quantity discounts based on an optional blanket ordering policy. The level of these discounts depends on :

1. The total volume ordered

2. The period of time over which the deliveries take place

The "spot" price of raw materials for the back-end suppliers will vary in a random way from the base level price, so that in certain circumstances the spot price in a period could be lower than the discounted price. Furthermore these raw materials will be subject to shortages in that one particular material may be unavailable in any particular month. These shortages will occur on a random basis without warning, although the (constant) probability of a shortage of any material in any month is known to participants. 
The above rules were designed over a period of many trials, and fairly extensive computations to reflect the type of advantages, disadvantages and trade-offs that would theoretically be derived from adopting alternative policies, and to ensure that no particular policy would, by simple computation, be "obviously" optimal in any particular set of circumstances. When a company decides to enter a long term agreement with either a customer or a supplier, it is basically making a trade-off between, on the one hand, the stability of demand and supply implied by such agreements, and on the other hand, the flexibility to respond to and take advantage of favorable short term variability in both volume and price, of immediate customer requirements and supplier capabilities.

\section{EXPERIMENTAL RESULTS}

The exercise was run on four separate occasions over a three year simulated period using different participants, in this case volunteer postgraduate students studying Supply Chain Management in Distance Learning mode over the Internet (over which all interactions in this exercise took place). The objective was to examine the types of collaborative partnership (if any) that emerged among individual companies over an extended time period, how these partnerships were managed, and their effects on profitability.

Results for a typical specimen run are shown graphically in Figure 2 for each of the three years, in which the relative numbers of customer-supplier interactions between pairs of companies are represented by the relative thickness of lines joining those companies. From this diagram, it can be clearly seen how distinct "virtual enterprises" do in fact evolve over time. In the first year, the relative numbers of interactions between customers and suppliers does not show any particular evidence of any preferred relationships. Clearly, during this period, participants are testing out different suppliers, and although post hoc analysis of participants decisions does indicate that in many cases, supply contracts of several months duration were established, these were frequently with more than one supplier for the same item, there was a relatively high frequency of change of supplier at the termination of the contract. During the second year, we start to see some better defined preferential partnerships developing as evidenced by the smaller number of thicker supply lines emerging. During the third year supply lines are further consolidated and it will be seen that almost all of the individual companies are now integrated into one or more clearly defined supply chains. What is also observed is a progressive narrowing of product range of front end companies over time. In the first year all of these companies manufactured at least three types of product. During the second year, all companies have started to restrict their product range. In the third year, no front-end company is producing more than two products, with one company $\left(S_{41}\right)$ only producing one product (D). 
First Year

Front end suppliers First tier suppliers Second tier suppliers Back end suppliers

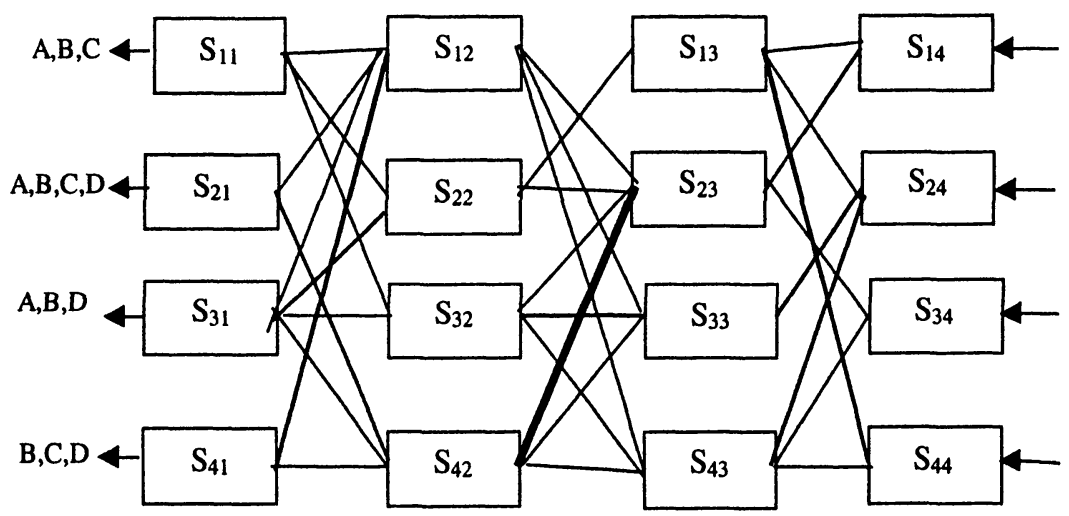

Second Year

Front end suppliers $\quad$ First tier suppliers Second tier suppliers Back end suppliers

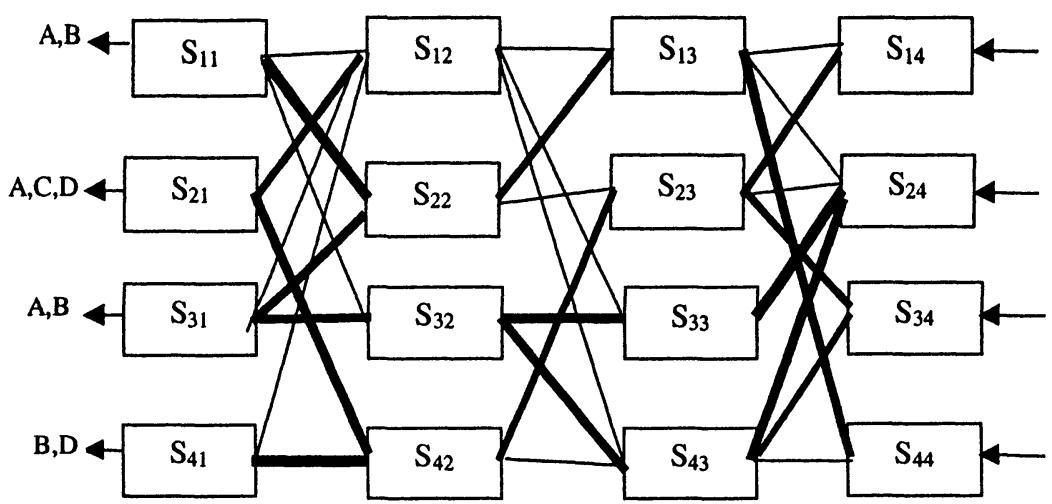

Third Year

Front end suppliers First tier suppliers Second tier suppliers Back end suppliers

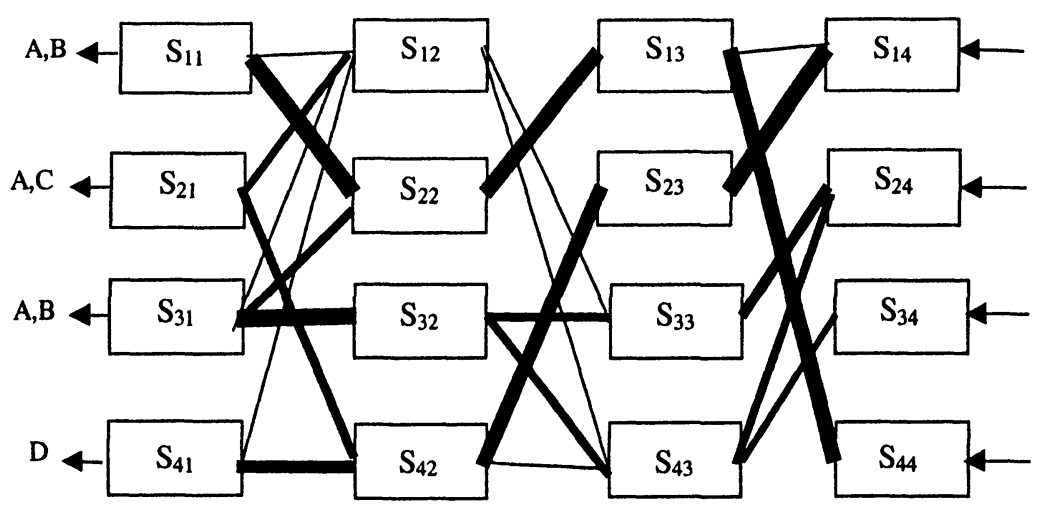

Figure 2 - Experimental Results 
The other three runs of this exercise with different groups of participants showed very similar results in terms of the emergence of a small number of dedicated supply chains, the specific chains emerging however being different in each case.

A more detailed analysis of the individual supply chains, their evolution and management revealed the following:

1. On examining the specific nature of the evolving cooperation, it was observed that this invariably commenced in the form of fixed term agreements with imposition (and enforcement) of the penalties for default of agreement as specified in the guidelines; however these penalties (which were stated to be optionally imposable on the defaulting party) were eliminated from existing agreements in favor of agreements that appeared to be based on mutual commitment and trust, rather than the threat of penalties. Thus although companies in the emerging virtual enterprises were entitled to exact penalties from companies that did not keep to agreements in the majority of cases they chose not to, ostensibly in the long term interests of the enterprise as a whole.

2. Evolving cooperation almost invariably lead to complete transparency of intended production plans between customer and supplier companies. This appears to be a further manifestation of enterprises operating on the basis of trust.

3. As individual companies increased that proportion of their business that was part of an integrated virtual enterprise, their individual profitability ratios (defined as the ratio of income from sales to total variable production and inventory holding costs) had improved by the third year by an average of $22 \%$ of their value in the first year.

4. The same companies showed an average drop in inventory levels of $36 \%$ between the first and third year of operation.

\section{CONCLUSIONS}

In the simulated industrial environment studied there appears to be a very strong tendency for companies (simulated by individual profit-maximising people) operating in a competitive demand-supply environment and involving several tiers of suppliers, to spontaneously evolve towards the formation of co-operative alliances that may be regarded as "virtual enterprises

Questionnaires put to participants at the conclusion of the exercise indicated that within the environment and set of rules under which they were operating, no specific course of action was identifiable as being specifically optimal from the point of view of strictly economical or mathematical analysis. Actual behaviour in this situation appeared to eventually be dominated buy co-operation and trust rather than any sense of economic rationalism, which might appear to suggest the dominance of of instinctive behavioural as opposed to rational optimising characteristics in these situations. Actual operating results obtained by individual companies on the other hand appear to improve with increasing levels co-operation and differentiation into individual networks.

Some quite profound research questions remain in relation to this initial study and these are currently under further investigation. . Specific issues being addressed 
are the extent to which individual behaviour in an artificially conceived gaming environment would directly map on to organisational behaviour in a real world environment. This particular study, rather than claiming that results from a simulated exercise that would have direct implications for the real world, is more of an exploratory nature to raise the issue of the extent to which the technique used (operational gaming) might produce valid and useful research results, and to contribute to the emerging dialogue on the nature and characteristics of virtual organisations.

\section{REFERENCES}

1. Erkollar A." Supply chain management, distributed planing and virtual enterprises - a new concept" Proceedings $5^{\text {th }}$ APRS Conference, Singapore July 2000

2. Erkollar, A.; Mayr, H.C. (1999): Planning in Virtual Enterprises Using the NETSIM Approach: an application report, In Proc. PICMET 99, Technology and Innovation Management, Portland, OregonUSA)

3. Larreche "MARKSTRAT3: The Strategic Marketing Simulation" College/West; 1997) 